\title{
Simulation of water column separation in Francis pump- turbine draft tube
}

\author{
C Niicolet $^{1}$, S Alligne ${ }^{1}$, A Bergant ${ }^{2}$ and F Avellan ${ }^{3}$ \\ ${ }^{1}$ Power Vision Engineering Sàrl, Ch. des Champs-Courbes 1, CH-1024 Ecublens, \\ Switzerland \\ ${ }^{2}$ Litostroj Power d.o.o., Litostrojska 50, 1000 Ljubljana, Slovenia \\ ${ }^{3}$ Laboratory for Hydraulic Machines, EPFL, Ecole Polytechnique Fédérale de \\ Lausanne, Av. de Cour 33 bis, CH-1007 Lausanne, Switzerland \\ E-mail: christophe.nicolet@powervision-eng.ch
}

\begin{abstract}
The paper presents the modelling, simulation and analysis of the transient behaviour of a $340 \mathrm{MW}$ pump-turbine in case of emergency shutdown in turbine mode with focus on possible draft tube water column separation. The model of a pumped storage power plant with simplified layout is presented. This model includes a penstock feeding one 340MW pumpturbine with the related rotating inertia and a tailrace tunnel. The model of the tailrace tunnel allowing for water column separation simulation is introduced. The simulation results of the transient behaviour of the pump-turbine in case of emergency shutdown in generating mode, with and without downstream water column separation model are presented for different degree of severity triggered by the submergence and the tailrace tunnel length. The amplitudes of the pressure peaks induced by the cavity collapse are analysed with respect to the pressure drop magnitude and tailrace dimensions. The maximum and minimum pressure amplitudes obtained along the tailrace tunnel are analysed for different test case conditions.
\end{abstract}

\section{Introduction}

Pumped storage power plants are subjected to transient operation resulting from units start-up, normal shutdown, emergency shutdown, power failure etc. Transient analysis is carried out at an early stage of the project to define the hydraulic layout of the power plant and to check the compatibility of the hydraulic machines transients with the foreseen adduction system. Special care has to be paid to high head projects, usually involving long penstock, high rotational speed, low inertia and short mechanical time constant, and low specific speed pump-turbines [1], [2]. The case of a pump-turbine emergency shutdown in generation mode is usually one of the most critical cases with respect to the maximum and minimum pressure induced in the piping system. Indeed, the pump-turbine reaches transient runaway and faces unstable behaviour related to the so-called S-shape of the pump-turbine characteristic [3], [4], [5], [6]. During runaway and guide vane closure, the transient operating point of the pump-turbine goes from the normal turbine operation in the first quadrant, to turbine brake and then to reverse pumping in the fourth quadrant. The excursion from normal turbine operation to reverse pumping being achieved in very short time, it leads to large and fast variation of discharge and thus generate high positive pressure wave in the penstock and negative pressure wave in the draft tube. If the penstock can be designed to withstand extreme value of the pressure, the minimum pressure in 
the draft tube has to be addressed with a particular attention to ensure sufficient safety margin to prevent from water column separation [7].

The paper presents the modelling, simulation and analysis of the transient behaviour of a $340 \mathrm{MW}$ pump-turbine in case of emergency shutdown in generation mode with particular attention to the possible draft tube water column separation. First, the model of a pumped storage power plant with simplified layout is setup with the EPFL software SIMSEN. This model includes a penstock feeding one $340 \mathrm{MW}$ pump-turbine with the related rotating inertia and a tailrace tunnel. The model of the tailrace tunnel allows for water column separation simulation. Thus, the related SIMSEN model is introduced. Finally, the simulation results of the transient behaviour of the pump-turbine with and without downstream water column separation are presented for different degree of severity triggered by the submergence and the tailrace tunnel dimensions taken as parameters.

\section{Modelling}

\subsection{Hydraulic components}

By assuming uniform pressure and velocity distributions in the cross section and neglecting the convective terms, the one-dimensional momentum and continuity balances for an elementary pipe filled with water of length $d x$, cross section $A$ and wave speed $a$, see Fig. 1, yields to the following set of hyperbolic partial differential equations [8]:

$$
\left\{\begin{array}{l}
\frac{\partial h}{\partial t}+\frac{a^{2}}{g A} \cdot \frac{\partial Q}{\partial x}=0 \\
\frac{\partial h}{\partial x}+\frac{1}{g A} \cdot \frac{\partial Q}{\partial t}+\frac{\lambda|Q|}{2 g D A^{2}} \cdot Q=0
\end{array}\right.
$$

The system (1), where $Q$ is the discharge and $h$ is the piezometric head, is solved using the Finite Difference Method with a $1^{\text {st }}$ order centered scheme discretization in space and a scheme of Lax for the discharge variable. This approach leads to a system of ordinary differential equations that can be represented as a T-shaped equivalent scheme [9], [10], [11] as presented in Fig. 2. The RLC parameters of this equivalent scheme are given by:

$$
R=\frac{\lambda \cdot|Q| \cdot d x}{2 \cdot g \cdot D \cdot A^{2}} \quad L=\frac{d x}{g \cdot A} \quad C=\frac{g \cdot A \cdot d x}{a^{2}}
$$

where $\lambda$ is the local loss coefficient. The hydraulic resistance $R$, the hydraulic inductance $L$, and the hydraulic capacitance $C$ correspond respectively to energy losses, inertia and storage effects. The model of a pipe of length $L$ is made of a series of $n_{b}$ elements based on the equivalent scheme of Figure 2. The system of equations relative to this model is set-up using Kirchoff laws. The model of the pipe, as well as the models of valve, surge tank, Francis turbine, etc, are implemented into the EPFL software SIMSEN, developed for the simulation of the dynamic behavior of hydroelectric power plants, [11], [12]. The time domain integration of the full system is achieved in SIMSEN by a Runge-Kutta $4^{\text {th }}$ order procedure. The modelling approach based on equivalent schemes of hydraulic components is extended to all the standard hydraulic components such as valve, surge tanks, air vessels, cavitation development, Francis pump-turbines, Pelton turbines, Kaplan turbines, pump, etc, see $[10]$. 


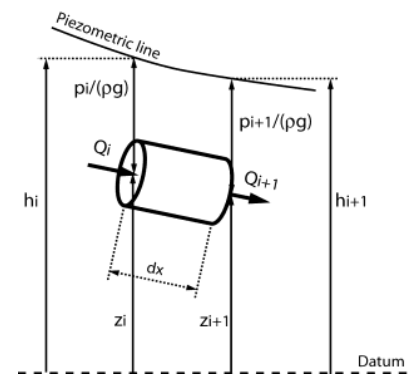

Figure 1. Elementary hydraulic pipe of length $d x$.

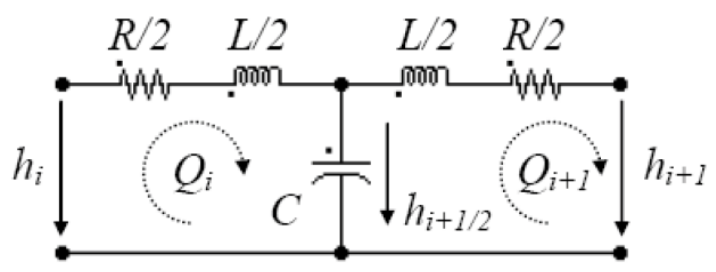

Figure 2. Equivalent circuit of an elementary pipe.

\subsection{Water column separation}

The free gas content of water significantly reduces the wave speed in pressurized pipelines, see [13], [14] and [15]. Wylie [14] derived wave speed in homogenous liquid free gas mixture characterized by an initial void fraction $\alpha_{o}$ defined for a reference absolute pressure $p_{o}$ and leads to the following equation:

$$
a=\frac{a_{o}}{\sqrt{1+\frac{p_{o} \alpha_{o} a_{o}{ }^{2}}{\rho g^{2}(h-Z-H v)^{2}}}}
$$

where :

$\begin{array}{clllll}a_{o} & {[\mathrm{~m} / \mathrm{s}]} & \text { Wave speed in liquid } & g & {\left[\mathrm{~m} / \mathrm{s}^{2}\right]} & \text { Gravitational acceleration } \\ p_{o} & {[\mathrm{~Pa}]} & \text { Reference absolute pressure } & h & {[\mathrm{~m}]} & \text { Piezometric head } \\ \alpha_{o} & {[-]} & \text { Initial void fraction } & Z & {[\mathrm{~m}]} & \text { Pipe elevation } \\ \rho & {\left[\mathrm{kg} / \mathrm{m}^{3}\right]} & \text { Liquid density } & H v & {[\mathrm{~m}]} & \text { Vapour pressure head }\end{array}$

Thus, the wave speed in liquid gas mixture is function of the local piezometric head. Figure 3 shows the wave speed evolution as function of the absolute gas partial pressure $(h-Z-H v)$ and of the initial void fraction $\alpha_{o}$. The non-linear equation (3) is introduced in the equation set (1) for time domain simulation so that the wave speed is local piezometric head dependant $a=a\left(h_{i}\right)$, similar to [16]. During water column separation the local piezometric head drops to very low values, and if the local pressure becomes negative due to numerical inaccuracy, the equation (3) leads to an increase of the wave speed, see [17]. Therefore, the wave speed is bounded to a minimum value defined as " $a_{\min }$ " to avoid numerical instability.

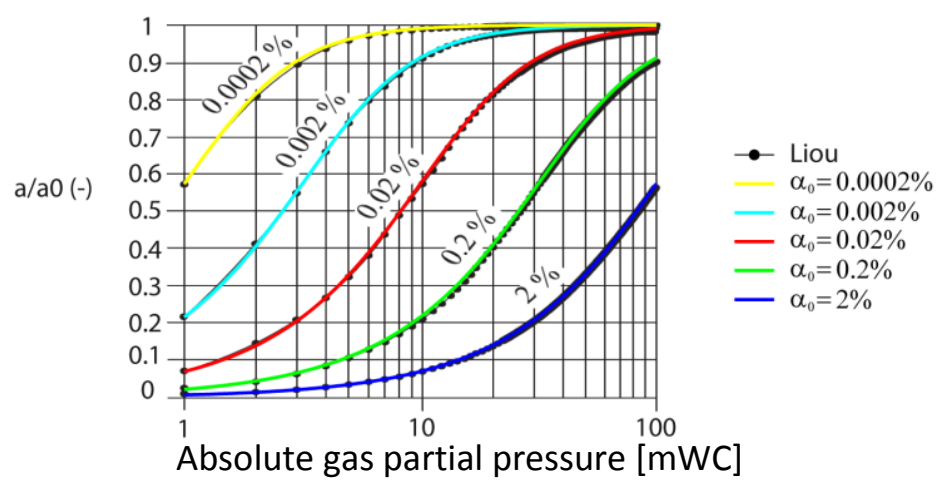

Figure 3. Wave speed ratio as function of the initial void fraction $\alpha_{o}$ and of the absolute gas partial pressure $(h-Z-H v)$ (adapted from Liou, [15]).

During water column separation, the bubbly liquid vapour mixture is subjected to dissipation resulting from phase changes. This dissipation is modeled by a thermodynamic damping $\mu$ " also 
known as the bulk viscosity or fluid second viscosity, see [18]. This thermodynamic damping is introduced in the numerical scheme by means of an additional thermodynamic resistance $\mathrm{R}_{\mathrm{th}}$ in series with the capacitance, see [19], and defined as follows:

$$
R_{t h}=\frac{\mu "}{A \rho g d x}
$$

The modified equivalent scheme of an elementary pipe with water column separation is presented in Figure 4 where the capacitance is pressure dependant. This water column separation model is implemented into SIMSEN and was validated with experimental data and also compared with Method of Characteristic, MOC, with Discret Gas Cavity Model, DGCM, results, see [17]. The test case, see [20], is a 37.23 meters long pipe of diameter 0.0221 meters with fast downstream valve closure inducing water column separation. The comparison between SIMSEN simulation results, MOCDGCM simulation results and experimental results have shown good agreement confirming the ability of the model to simulate water column separation if appropriate set of parameters is selected, see [17].

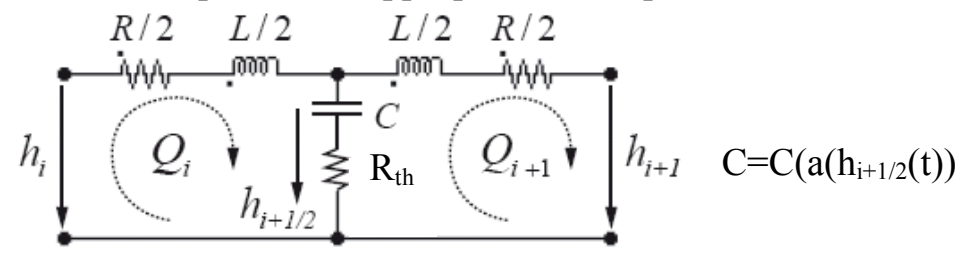

Figure 4. Equivalent scheme of an elementary pipe with water column separation including pressure dependency of the wave speed and thermodynamic damping.

\section{Case study}

The case study is a hydroelectric power plant with a simplified layout as illustrated in Figure 5 made of an upstream reservoir with constant water level, a penstock of about 1100 meters long and 6.4 to 3.6 meters of diameter, a pump-turbine of $340 \mathrm{MW}$ which nominal parameters are given in Table 1 , and a tailrace tunnel of 150 meters long and 4.7 meters of diameter. The pump-turbine is modelled by the 4 quadrant characteristics given by the guide vane opening $y$, the speed factor $\mathrm{N} 11$, the discharge factor Q11 and the torque factor T11, and the inertia of the total rotating masses $J$.

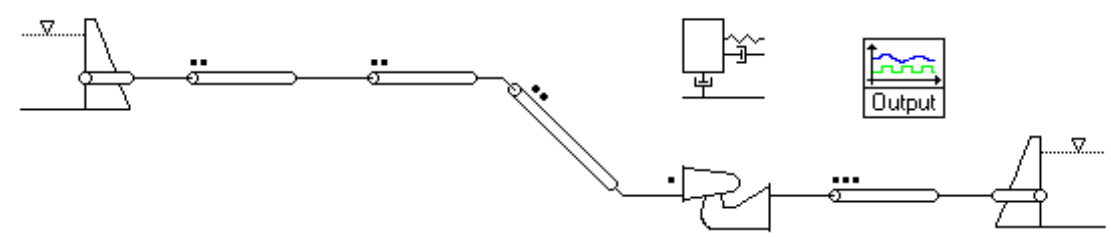

Figure 5. SIMSEN model of the pump-turbine case study with simplified layout.

Table 1. Rated values of the pump-turbine of Figure 5.

\begin{tabular}{cc}
\hline parameter & value \\
\hline HR [m] & 440 \\
QR [m3/s] & 86 \\
NR [rpm] & 428.6 \\
PR [MW] & 340 \\
$v[-]$ & 0.26 \\
J [ kgm2] & 1.5 .106 \\
\hline
\end{tabular}




\section{Francis Pump-turbine transient and possible draft tube water column separation}

4.1. Pump-turbine transient in case of emergency shutdown in generating mode

Figure 6 presents the simulation results obtained with SIMSEN for the transient behaviour of the pump-turbine of the system shown in Figure 5 in case of emergency shutdown in generating mode occurring at $t=1 \mathrm{~s}$ and with guide vane closure in $T_{c}=25 \mathrm{~s}$. Figure 7 shows the transient operating point experienced by the pump-turbine during the emergency shutdown in the [N11-Q11] plane with the guide vane opening as parameter. One can notice that after disconnection from the grid, the pump turbine experiences rotational speed rise inducing an increase of N11 and thus a fast discharge reduction leading to a negative discharge due to the so-called S-shape of the pump-turbine characteristic [1], \{2]. The fast discharge reduction produces positive water hammer pressure wave in the penstock and negative pressure wave in the tailrace tunnel resulting in a net head increase. During the guide vane closure, the pump-turbine experiences two times unstable behaviour with excursions in the fourth quadrant corresponding to reverse pumping with negative discharge and positive rotational speed.

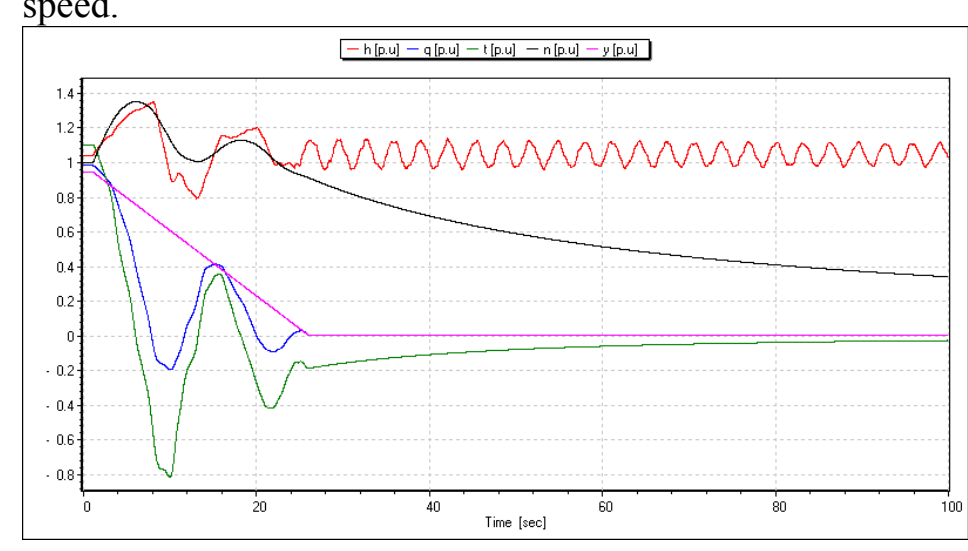

Figure 6. Pump-turbine transient behaviour in case of emergency shutdown in generating mode with $h$ the net head, $q$ the discharge, $t$ the torque, $n$ the rotational speed and $y$ the guide vane opening all related to rated values.

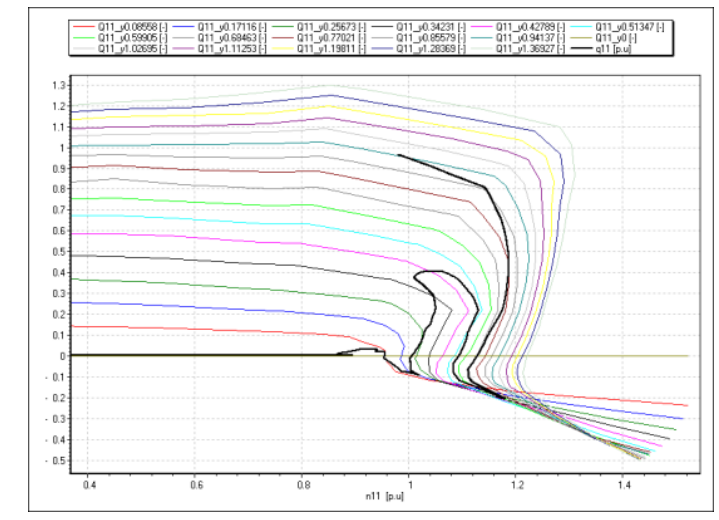

Figure 7. Pump-turbine transient operating point in case of emergency shutdown in generating mode in the N11-Q11 plain.

\subsection{Draft tube water column separation}

The transient behaviour of the system with the pump-turbine of Figure 5 is simulated with the model of water column separation for the tailrace tunnel in case of emergency shutdown, ESD, in generating mode. The water column separation is induced by modifying the submergence and the tailrace tunnel length as follows:

- Case A) the tailrace water level is reduced by $15 \mathrm{~m}$ to obtain a minimum negative pressure in the draft tube $5 \mathrm{mWC}$ below the vapour pressure during ESD, when using the classical water hammer model without column separation;

- Case B) the tailrace water level is reduced by $20 \mathrm{~m}$ to obtain a minimum negative pressure in the draft tube $10 \mathrm{mWC}$ below the vapour pressure during ESD, ditto;

- Case C) the tailrace water level is reduced by $25 \mathrm{~m}$ to obtain a minimum negative pressure in the draft tube $15 \mathrm{mWC}$ below the vapour pressure during ESD, ditto;

- Case D) the tailrace water level is reduced by $20 \mathrm{~m}$ and the tailrace water tunnel length is doubled to obtain a minimum negative pressure $28 \mathrm{mWC}$ below the vapour pressure during ESD, ditto.

The simulation results obtained for the cases A) to D) with and without the water column separation model are presented in Table 2. As expected, for the four cases, water column separation occurs and then leads to vapour cavity collapse resulting in sudden pressure rise which maximum amplitudes are 
reported in Figure 8. The maximum pressure amplitudes obtained for cases A) to D) shows monotonic increase when the minimum pressure value obtained without water column separation decreases. For the case D), the maximum pressure obtained in the draft tube, reaches $366 \mathrm{mWC}$ and corresponds to $82 \%$ of the nominal head, and thus would considerably jeopardize the power plant integrity. Comparison of cases B) and D) shows the detrimental influence of increasing the tailrace tunnel length, leading to a lower minimum pressure and thus a higher maximum pressure value resulting from cavity collapse, see also [21]. The envelops of extreme pressure values obtained along the tailrace tunnel are presented in

Figure 9. For each test case, the water column separation occurs in $95 \%$ of whole tailrace tunnel and the related collapses induce high pressure values extending over 80 to $90 \%$ of the tunnel even for locations close to the downstream reservoir where high pressure values are usually not expected. Figure 10 and Figure 11 shows the transient behaviour of the pump-turbine obtained for the case D) with water column separation. Due to water column separation and related net head changes, the pump-turbine experiences several S-shape back and forth excursions that would represent an increase of the machine components loading.

Table 2. Time evolution of the pressure at the inlet of the draft tube obtained with the pump-turbine in case of emergency shutdown in generating mode with and without water column separation model for cases A) to D).

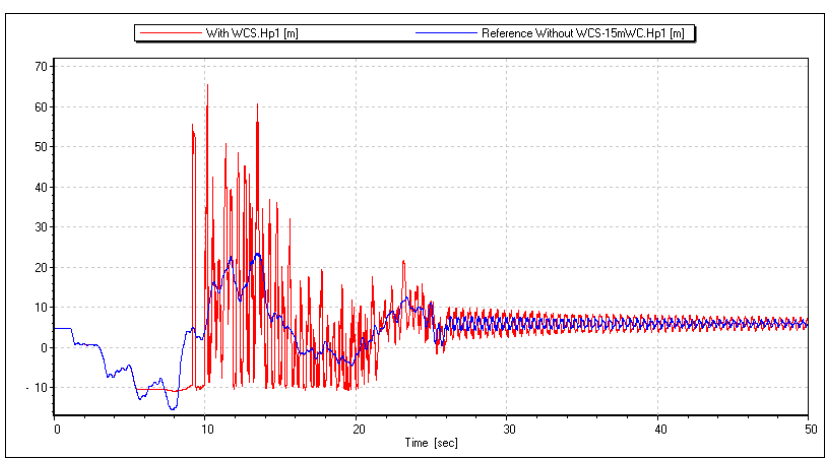

Case A)

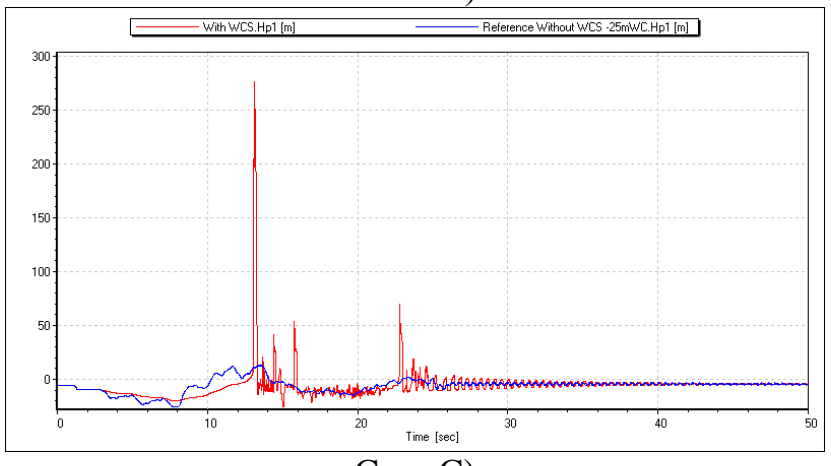

Case C)

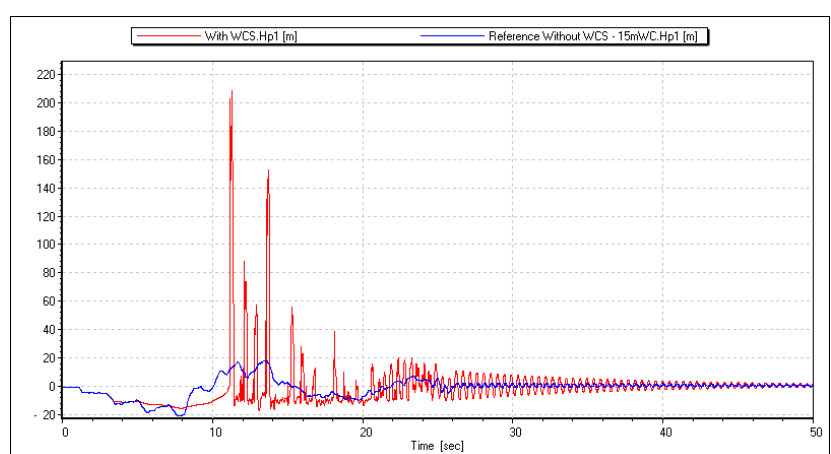

Case B)

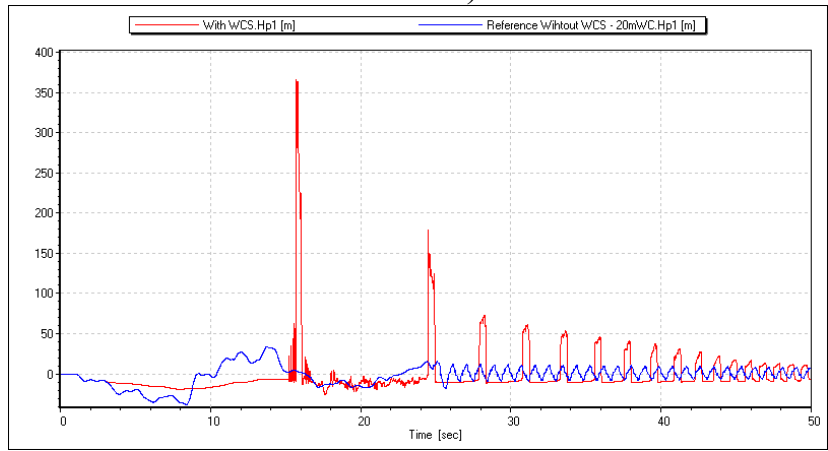

Case D)

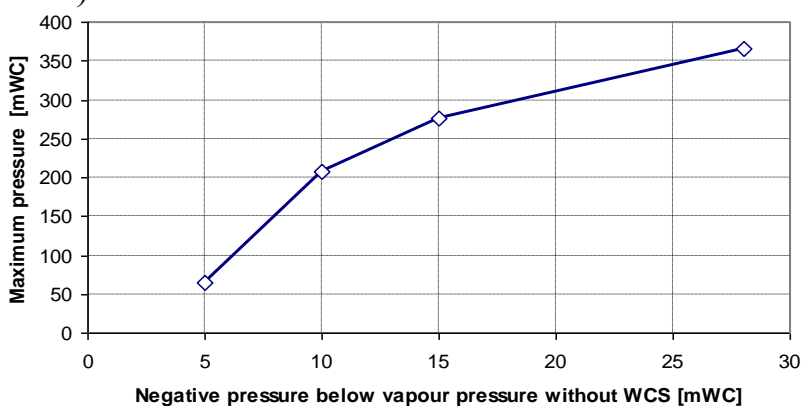


Figure 8. Evolution of the maximum overpressure above atmospheric pressure as function of the negative pressure obtained in tailrace tunnel without water column separation model.

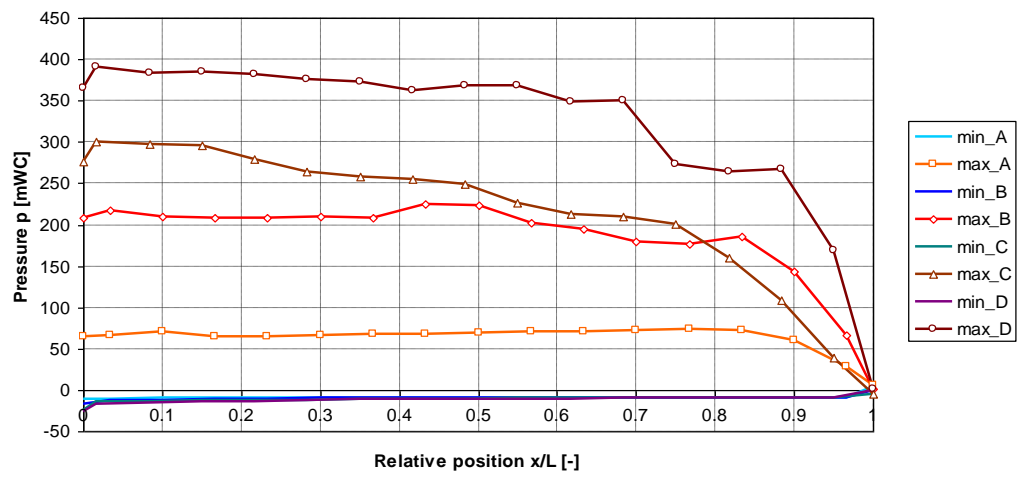

Figure 9. Envelops of maximum and minimum pressure values obtained in the tailrace tunnel for the cases A) to $\mathrm{D})(\mathrm{x} / \mathrm{L}=0$ : pump-turbine draft tube ; $\mathrm{x} / \mathrm{L}=1$ : downstream reservoir).

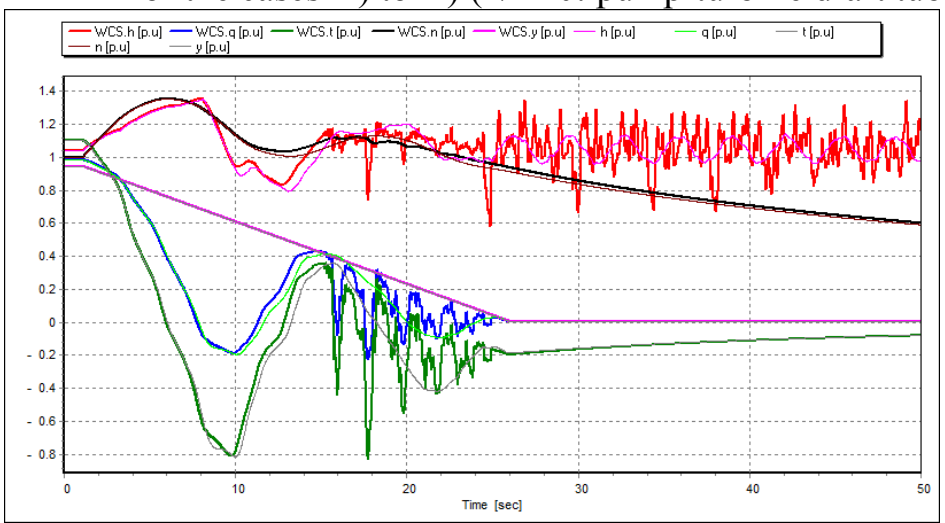

Figure 10. Comparison of pump-turbine transient behaviour in case of emergency shutdown in generating mode with and without water column separation (WCS) for case D).

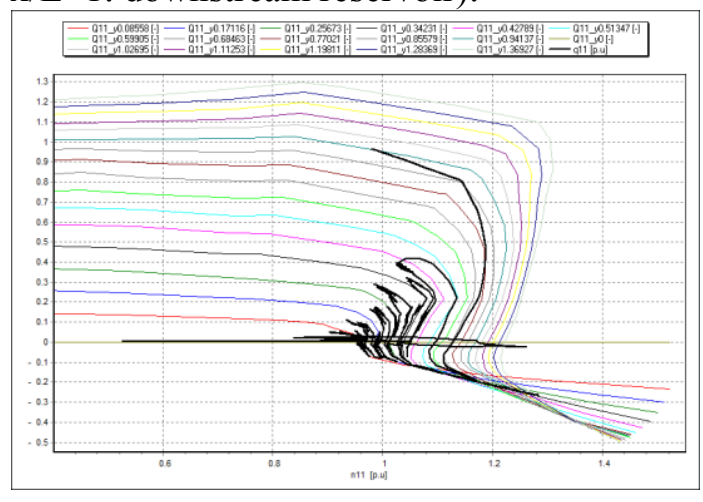

Figure 11. Pump-turbine transient operating point in the N11-Q11 plain for the case D) with water column separation.

\section{Conclusions}

This paper presents the modelling, simulation and analysis of possible water column separation in pump-turbine draft tube which could occur during emergency shutdown in generating mode using the simulation software SIMSEN. It is shown for cases with water column separation, that the pressure rise resulting from the vapour cavity collapse may reach high maximum pressure values extending over almost the entire tunnel, and thus jeopardize the power plant integrity. The detrimental effect of increasing the length of tailrace tunnel on minimum pressure in draft tube, and thus, on the risk of water column separation, is also pointed out. The water column separation model implemented into SIMSEN, combined with the already existing hydraulic machines and components models allows estimating the severity of such unwanted event. However, the influence of the cavitation development in the draft tube on the pump-turbine characteristic has not been considered so far.

\section{References}

[1] Pejovic S, Krsmanovic L, Jemcov R and Crnkovic P 1976 Unstable operation of high-head reversible Pump-Turbines. Proc. of the 8th IAHR Symp. on Hydraulic Machinery and Systems (Leningrad, Russia, 1976) pp 283-295

[2] Taulan J P 1983 Pressure surges in hydroelectric installations - Peculiar effects of low specific speed turbine characteristics Proc. 4th BHRA Int. Conf. on Pressure Surges (Bath, UK, 1983) Paper H2 pp 337-351 
[3] Huvet P 1992 Steady oscillation between pump-turbine operating at partial flow and surge shaft. Proc. 16th Symposium of the IAHR (Sao Paulo, Brazi, 1992)

[4] Martin, C. S., (1986). - Stability of pump-turbines during transient operation. Proc. of the 5th Int. Conf. on Pressure Surges (Hannover, Germany, 1986) pp 61-71 paper C3

[5] Martin C S 2000 Instability of pump-turbines with s-shaped characteristics Proc. of the 20th IAHR Symp. on Hydraulic Machinery and Systems (Charlotte, USA, 2000)

[6] Nicolet C, Alligné S, Kawkabani B, Simond J-J and Avellan F 2008 Unstable operation of Francis Pump-Purbine at runaway: rigid and elastic water column oscillation modes Proc. of the 24th IAHR Symp. on Hydraulic Machinery and Systems (Foz do Iguassu, Brazil, 27-31 October 2008) p150.

[7] Pejovic S 2010 High head pump turbine "S" instability huge risk for draft tube water column separation Proc. HydroVision International (Charlotte, NC, USA, 27-30 July 2010)

[8] Wylie E B and Streeter V L 1993 Fluid Transients in Systems (Englewood Cliffs:Prentice Hall)

[9] Paynter H M 1953 Transaction of ASCE 146 962-1009.

[10] Nicolet C 2007 Hydroacoustic Modelling and Numerical Simulation of Unsteady Operation of Hydroelectric Systems PhD Thesis (EPFL n³751, Lausanne, http:// library.epfl.ch/theses/?nr=3751)

[11] Souza O H J, Barbieri N and Santos A H M 1999 IEEE Transactions on Power Systems 14(4) 1269-72

[12] Sapin A 1995 Logiciel modulaire pour la simulation et l'étude des systèmes d'entraînement et des réseaux électriques Thesis EPFL $n^{\circ} 1346$ (http://library.epfl.ch/theses/?nr=1346)

[13] Bergant A, Simpson A R and Tisseling A S 2006 J. Fluids and Structures 22(2) 135-171

[14] Wylie E B 1984 J. Fluids Eng. 106(3) 307-11

[15] Liou J C P 2000 Transients. J. Fluids Eng. 122(3) 636-639

[16] Himr D and Haban V 2009 Simulation of low pressure water hammer Proc. of the 25th IAHR Symp. on Hydraulic Machinery and Systems (Timisoara, Romania, 20-24 September 2009) paper 1B.3

[17] Nicolet C, Kaelbel T, Alligné S, Ruchonnet N, Allenbach P, Bergant A and Avellan F 2011 Simulation of water hammer induced column separation through electrical analogy. Proc. of the 4th IAHR Int. Meeting of the WorkGroup on Cavitation and Dynamic Problems in Hydraulic Machinery and Systems (Belgrade, Serbia, 26-28 October 2011)

[18] Pezzinga G 2003 J. Hydraulic Research 41(6) 656-65

[19] Alligné S, Nicolet C and Avellan F 2011 Identification of Francis turbine helical vortex rope excitation by CFD and resonance simulation with the hydraulic system Proc. of ASMEJSME-KSME Joint Fluids Engineering Conference (Hamamatsu, Japan, 2011)

[20] Bergant A and Simpson A 1999 J. Hydraulic Eng 125(8) 835-48

[21] Nicolet C, Alligne S, Bergant A and Avellan F 2011 Parametric study of water column separation in Francis Pump-turbine draft tube Proc. of SHF «Pumped storage Powerplants» (Lyon, France, 23-24 November 2011) paper 20 